\title{
A Case Study of the Practical Implications of Using Interactive Technology in Teaching International Postgraduate Students
}

\author{
Samer Skaik \\ School of Engineering and Technology, Central Queensland University, Melbourne, Victoria 3000, Australia \\ ORCID: 0000-0003-2154-0201 \\ Roksana Jahan Tumpa \\ School of Engineering and Technology, Central Queensland University, Sydney, NSW 2000, Australia \\ ORCID: 0000-0003-4721-5300
}

Received: 28 Jun 2021

Accepted: 26 Sep 2021

\begin{abstract}
Many educators struggle to engage or stimulate students to actively engage in classes. International students, in particular, are more vulnerable to the risk of disengagement due to their competing priorities and social barriers. The use of interactive technology can promote active learning and facilitate better student experience and inclusion. This case study aims to examine the practical implication of one of the popular interactive technologies on the learning experience of international students. The study revealed that adopting the interactive technology in lectures had an obvious positive impact on student learning experience, attainment of learning outcomes, and motivation levels. It helped students engage genuinely in the assessment tasks and have their voice heard without fear or influence by faculty or peer pressure. The study also identified some challenges including the lead time required for training both faculty and students on using the technology more effectively. The study contributes to the existing knowledge by providing evidence-based implications of using interactive technology in higher education.
\end{abstract}

Keywords: active learning, interactive technology, international students, Mentimeter

\section{INTRODUCTION}

In the digital age, the availability of innovative technologies provides a great opportunity for educators to move away from teacher-centred learning (McGarr, 2009). Teacher-centred learning may not be helpful to international students who usually feel reluctant to engage in class activities due to cultural and language barriers (Andrade, 2006). Those students have competing priorities such as settling in a new country and working to fund their studies and may not have the motivation to engage genuinely in their studies (Brimble, 2016). Furthermore, peer pressure plays a major role in holding students back in a classroom and therefore, their engagement becomes so limited (Zhou et al., 2008). Engaging those students becomes more problematic in units that are typically dry and boring such as research methods units (Sillaots, 2014; Winn, 1995).

The appropriate use of technology can help address the lack of student engagement (Rashid \& Asghar, 2016). Many online interactive tools are currently available that can serve this purpose such as Socrative, Mentimeter, GoSoapBox, and Poll Everywhere. Such tools adopt different approaches to developing interactive content for educational purposes which was proven to be effective in engaging learners, especially in large groups (Little, 2016; Mayer et al., 2009). Many studies have examined the impact of using various interactive technological tools on student education in different contexts (e.g., Gokbulut, 2020; 
Heaslip et al., 2014; Khalili \& Ostafichuk, 2018; Skoyles \& Bloxsidge, 2017; Van Daele, et al., 2017; Wood, 2020) but there is little research conducted to thoroughly understand the practical implications of using such interactive technology on the learning experience of international students. Accordingly, this case study aims to understand the practical implications of adopting Mentimeter, as one of the emerging interactive technologies, and carefully examine whether the learning experience of international students was significantly improved.

\section{LITERATURE REVIEW}

\section{The Problems Encountered by International Students}

International students undergo a number of challenges when it comes to pursuing their higher studies in a foreign country. The major adjustments international students make range from cross-cultural adaptations to language difficulties and financial pressures to academic challenges (Introna et al., 2003).

The language barrier is one of the most common issues and dominant problems faced by international students in a foreign country (Heng, 2018; Novera, 2004; Sawir, 2005; Sawir et al., 2012; Yue \& Fan, 2010). International students' lack of proficiency in English prevents them from studying in English-speaking countries (Zhang \& Mi, 2010). International students face language barriers both in academic (Yanagi \& Baker, 2016) and social (Khawaja \& Stallman, 2011) contexts. They also demonstrate a lack of confidence to communicate with their peers because of their language inefficiency and inability to understand peers' accents (Sawir, 2005). Inadequate command over English resulted in subject-wise incomprehensive analysis and reduced reading efficiency (Phakiti \& Li, 2011). Furthermore, students feel uncomfortable participating in the class discussion because of the language barrier (Hellsten \& Prescott, 2004; Robertson et al., 2000). They feel shy and hesitant to talk to lecturers and tutors (Khawaja \& Stallman, 2011). The same arguments were echoed in Wang and Shan's (2007) and Wong's (2004) studies.

In addition to the language barrier, international students experience difficulties in coping with the education systems of a foreign university. The difficulty international students face in academic transition is named 'academic shock' (Sovic, 2008). The tertiary education system in Australia is completely different from that of Asian countries (Novera, 2004; Sanner \& Wilson, 2008; Wang et al., 2015; Wang \& Shan, 2007; Wong, 2004; Yu \& Wright, 2016; Yue \& Fan, 2010). International students showed anxiety about the education system in Australia (Khawaja \& Stallman, 2011). The education pedagogy in Australia varies from its counterparts in Asian countries in terms of assessment design as well as teaching and learning styles (Khawaja \& Stallman, 2011).

The difference in teaching and learning styles poses a significant challenge to international students. The major concerns are students' limited thinking, teacher-centred learning, and limited participation in class discussion (Wang et al., 2015). In Australia, education is more student-centric and based on practical knowledge rather than theoretical knowledge (Wang \& Shah, 2007). Unacquainted and uncertain pedagogy is a pivotal challenge to international students particularly in terms of assessment arrangements. While the assessments in Asian countries are mainly based on final examinations and rote learning, assessments in Australia are based on multiple assessment submissions, oral presentations, case studies, class participation, and examinations (Wang \& Shan, 2007; Wong, 2004). In Australian universities, students are not expected of rote learning, instead, they need to apply their learned knowledge in different scenarios (Khawaja \& Stallman, 2011).

In a similar vein, financial problems take a toll on international students. Financial problems have been identified as a crucial concern that significantly affects students' academic life. Having no family and relatives, it is hard for them to cope with living and academic costs. Due to the enormous tuition fees, limited access to loans, less possibility of getting scholarships, and being unable to work off-campus, international students experience more burden and pressure than domestic students (Poyrazli \& Grahames, 2007). Faced with several challenges along with financial difficulties, international students easily lose track and focus of their 
studies while working to make their survival in a foreign land. Similar conclusions were reached in the study of Cowley and Hyams-Ssekasi (2018).

In addition to language, academic and financial barriers, the psychological stress of international students has been on the rise. The psychological issues include problems in relationships, poor friendship, depression, and a high level of anxiety (Kambouropoulos, 2014). Psychological distress stems from various social-cultural challenges including culture shock, loneliness, worry, and ruminations (Yu \& Wright, 2016). International students' initial stages of their sojourn are not a period of excitement rather associated with adverse psychological stress leading to cultural shock (Gomes et al., 2014). International students suffer more from psychological distress than domestic students in academic and social adjustments (Andrade, 2006) as they face many challenges in a foreign land. During their initial sojourn, they are highly affected by loneliness and anxiety. Loneliness and disconnectedness were perceived extremely by international students because of the lack of friendship, especially with their Australian peers. This problem can largely be attributed to their language barrier (Kambouropoulos, 2014).

Taken together, international students face several academic and non-academic challenges. Therefore, it is highly likely that these students may feel disengaged, demotivated in their studies, and frustrated which may easily side-track them from their studies.

\section{The Evolvement of Interactive Technology}

It is a daunting task for instructors to gauge students' understanding of materials in large classrooms (Funnell, 2017; Van Daele et al., 2017). Sometimes, students feel reluctant to raise their hands and ask questions (Kuritza et al., 2020) which may negatively impact their class engagement and learning. To address this issue, the Audio Response System (ARS) has been used since 1985 to promote student-teacher interaction in small and large classrooms (DeBourgh, 2008; Duggan et al., 2007). The extant literature implies a range of names for ARSs such as student response systems (Cain et al., 2009), immediate response systems (Yourstone et al., 2008), electronic feedback systems (Brady et al., 2013), classroom communication systems (Paschal, 2002) and classroom performance system (Petersohn, 2008). ARSs have the potential to bring a pedagogical shift from a teacher-centred to student-centred learning environment and promote active learning. In addition to that, ARSs render a plethora of advantages such as tracking and maintaining in-class engagement levels, evaluating the effectiveness of individual lectures, and understanding students' learning experiences (BlascoArcas et al., 2013; Kulatunga \& Rameezdeen, 2014).

There are two types of ARSs used in higher education: clickers and online tools (Funnell, 2017). 'Clickers' is one of the popular student response systems which has been discussed extensively in the literature. Clickers were first introduced in the 1960s (Hunsu et al., 2016), however, the commercial utilisation of clickers has not started until 1992 (Abrahamson, 2006). Secondary and post-secondary education have realised clickers' benefits in classrooms since 2003 (Abrahamson, 2006) and clickers have substantially evolved in terms of capacities, forms, and availabilities (Hunsu et al., 2016). Clickers require a small hand-held device, known as clickers, and a computer software program that receives signals from the handheld device (Fies \& Marshall, 2006). Relevant software needs to be installed on the presentation computer and a dongle used for wireless connectivity. TurningPoint and iClicker are a few examples of this technology (Funnell, 2017). Clickers have gained enormous popularity in teaching and learning pedagogy (Blasco-Arcas et al., 2013; Kulatunga \& Rameezdeen, 2014; Reay et al., 2005). This technology promoted a high level of interactivity with peers and teachers, fostered collaborative learning, and increased engagement in the classroom (Blasco-Arcas et al., 2013).

In the past few years, online advanced ARSs have emerged including Poll Everywhere, Mentimeter, and Socrative. Unlike clickers, the online ARSs are cloud-based, and students can bring their own devices for class participation. The tools serve as a "middleman" to receive, tabulate and present the data collected. In this study, the authors selected a case study whereas Mentimeter was used. This user-friendly tool does not require setup or installation which alleviates a lot of hassle in installation (Rudolph, 2018). 


\section{Using Mentimeter in Education}

Mentimeter facilitates developing interactive slides for use in classrooms. Students can connect to the slides by using any device connected to the internet, such as smartphones or laptops. Students are required to enter a six-digit code to respond to the questions, pose questions on the screen or make any comment anonymously (Mayhew, 2019). Educators can design the presentation in the Mentimeter platform online to suit their requirements. The advanced quiz functionality is one of the most popular features of Mentimeter where students can compete in an entertaining environment. Another interesting feature of Mentimeter is the utilisation of word clouds which is a fun way to engage students and understand their perceptions or assess their knowledge about the learned content (Mayhew, 2019).

A case study conducted by Lin and Lin (2020) examined the use of Mentimeter in light of specific communication theories and its impact on the teaching effectiveness and enhancement of educational communication skills. The study revealed that the tool improved the process of recapping. Another study found that the utilisation of Mentimeter was well received by medical students who found the tool beneficial in improving their understanding of historically complex concepts and preparing them for their exams (Kuritza et al., 2020). The study also revealed that real-time feedback helped students understand their knowledge retention. Wood (2020) surveyed and interviewed undergraduate geography students to understand their attitude and reaction towards Mentimeter. In this study, students conceded that Mentimeter was very helpful to gauge their understanding of the material taught, make the classroom more exciting and engaging, improve their participation and allow them to compare their answers with their peers.

Although Mentimeter reduces logistics in comparison to clickers (Van Daele et al., 2017), Funnell (2017) empirically investigated the relative effectiveness between clickers and online ARSs such as Mentimeter or Socrative, or a combination of both. Two cohorts of medical students were surveyed to examine their experiences in using clickers and online ARSs. Online ARSs, especially the Mentimeter's word cloud feature induced significant excitement in the class. The cohort using Mentimeter expressed increased levels of satisfaction and confidence compared to the other cohort using clickers. Van Daele et al. (2017) studied the impact of using Mentimeter in teaching the second-year bachelor students of Applied Psychology. The study revealed that the tool helped students engage more effectively in the classroom by allowing them to ask questions anonymously. Similarly, Khalili and Ostafichuk (2018) conducted a pilot study on using Mentimeter and found that students were more comfortable asking questions via Mentimeter rather than asking verbally. The study concluded that the tool addressed the different needs of students.

From the academics' point of view, Mentimeter was found easy to use, as it did not entail any special software or hardware (Funnell, 2017; Van Daele et al., 2017). Wood (2020) divulged that the experience of academics was dependant on their teaching styles and their previous experience with Mentimeter. Wood (2020) further argued that Mentimeter should be integrated across the programme so that students and teachers can use the tool effortlessly.

Although Mentimeter has exhibited its potential to improve students' engagement, interaction and make them feel included in the classroom, existing literature indicates some potential limitations including the need for a stable internet connection (Funnell, 2017; Lin \& Lin, 2020; Van Daele et al., 2017) and supportive technology (Wood, 2020). Educators warned that the anonymity feature makes it difficult to identify a particular student based on their contribution and engagement level (Lin \& Lin, 2020). Kuritza et al. (2020) asserted that the anonymity feature may encourage some students to be free riders and they may feel reluctant to contribute their answers.

\section{RESEARCH METHOD}

A single qualitative case study approach was adopted in this research. The case study is one of the most frequently used methods which helps to explore a phenomenon in a 'real-life context' (Baxter \& Jack, 2008; Yazan, 2015). By using a single case study approach, this research aims to investigate the practical implication of using Mentimeter on the learning experience of international students. The data were collected through two main sources: 1) first-hand observation, and 2) analysis of available secondary data. The first-hand 
observation was made by the first author who was also involved in coordinating and teaching the unit. The secondary data were mainly retrieved from the unit metrics as well as the interim and final unit evaluation surveys. In both surveys, students were provided with several 5-point Likert scale questions and two openended questions. The quantitative data were analysed using descriptive statistics while the qualitative data from open-ended questions were coded and thematically analysed using NVivo.

\section{Validity and Credibility}

In qualitative research, validation is the process of determining whether the results are accurate from the researchers', participants', or readers' points of view (Creswell, 2009). One of the ways of increasing the credibility of qualitative case studies is triangulation (Yin, 2014). Triangulation involves the use of multiples sources to obtain rich data to increase the conformity of the research results (Regmi, 2014). In this study, data triangulation was employed. Data triangulation "involves the collection of data from different types of people, including individuals, groups, families, and communities, to gain multiple perspectives and validation of data" (ONF, 2014, p. 545). In this study, multiple data sources were used. The firsthand observation was used as the first source to triangulate the data collected through the two surveys. The surveys used a range of questions to triangulate the results of the observation. The findings of the three data sources appeared to have a good alignment as evident by the results of the study.

\section{Code Reliability}

To improve the trustworthiness of the coding process of the open-ended questions, the process discussed in Lincoln and Guba (1985) was closely followed. Once the authors screen all of the data from the open-ended questions, initial coding was conducted. This process involved the initial production of codes with keep revisiting the data. Initial coding was conducted on a spreadsheet then exported to NVivo for further review and analysis. The coding review process was conducted through peer debriefing between the two authors to improve the credibility of the process (Nowell et al., 2017). Both authors gave full and equal attention to the data of the open-ended questions (Nowell et al., 2017). Individual extracts of data were inserted in the findings as many times as deemed relevant (Nowell et al., 2017). Subsequently, themes were formed inductively without trying to fit into any pre-existing coding framework as discussed in Nowell et al. (2017). Both authors then reviewed the themes concerning the objectives of the research. While reviewing themes, some of the themes were excluded as there were not enough data to support that. Upon reviewing the themes, the authors wrote a detailed analysis of each theme. Both authors reviewed the names of themes, and the themes were not finalised until they were read and scrutinised by both of the authors. Through peer debriefing, both authors agreed on how to present the themes to complete the story which ultimately addressed the research objectives. Both authors also revised the names of the themes several times. Finally, the report was established. The discussion of the findings involved quotes where relevant.

\section{The Context}

The full version of Mentimeter was introduced in the second term of 2018 in a postgraduate research methods unit nested within the Master of Project Management course at an Australian university. In that term, 241 international students enrolled in the unit across four metropolitan campuses as compared to 81 students enrolled in the previous term. The unit was delivered weekly via two-hour lectures and two-hour tutorials over twelve weeks. Six lecturers were involved in the delivery of the unit including the first author.

In the previous offerings of the unit, it was noted that the class attendance and in-class participation were relatively low. To address the low engagement, the unit coordinator, informed by the literature findings, decided to introduce Mentimeter as an interactive tool. The unit coordinator attributed the lack of engagement to multiple factors including the dry nature of the unit and traditional teaching strategies as well as cultural and language barriers facing international students. As such, it was hypothesised that the introduction of an interactive tool such as Mentimeter in classes would address these challenges and transform the classroom into a more vibrant student-centred environment. 


\section{The Approach to Using the Tool in Lectures}

The full team license of Mentimeter was procured in term 2, 2018. The team license facilitates sharing of the prepared interactive slides with other teaching staff. Two weeks before the start of the term, the unit coordinator introduced the tool to the teaching team and delivered a training session to help them get started. To reinforce the objective of student-centred learning, a semi-flipped class model was also adopted. Students were requested to review the static lecture slides along with a short video and come prepared to each class. The lecturer then started his presentation with a few interactive questions using Mentimeter to gauge the level of student preparation and understanding of key concepts so the lecturer could adapt his delivery plan according to students' needs. The lecturer also posed interactive questions at different times throughout the lecture to maintain the interactive vibe in the classroom and reinforce student understanding. In case of a significant disparity in students' answers to a certain question, the lecturer posed the same question again but required the students to discuss the posed question in pairs before proceeding to the second attempt. Aided by Mentimeter, it was handy for the lecturer to visually compare the two answers via a bar chart diagram to demonstrate the learning development of students.

Throughout the lecture timing, students were allowed to pose anonymous questions or make comments relating to the presented content. A notification of the posed questions appeared instantly on the screen and the lecturer had the discretion to pause teaching to answer the posed questions or wait until the end of the lecture to answer all posed questions during the Q\&A session. Towards the end of the lecture, students were requested to participate in a competitive quiz of several questions ranging between 6-10 questions in each lecture. The quiz was used as a formative assessment of student learning, and it provided students with one more opportunity to polish their understanding of the learned concepts in the lecture. To participate in the quiz competition, students had to choose unique avatars and provide nicknames to participate in the quiz. The winner of the quiz was calculated automatically by the tool based on the accuracy and speed of posting the answers. A leader board of the top participants was shown on the interactive slides after completing each patch of quiz questions.

\section{CASE STUDY FINDINGS}

\section{Firsthand Participant Observations}

The first author happened to be the unit coordinator of the unit examined in this case study. As observed, it was the first time for the teaching team to use interactive technology in this unit. As such, it took the unit coordinator a few days to navigate through the tool features and start developing interactive slides before the commencement of the term. One of the six lecturers involved in the unit in that term was reluctant to use Mentimeter preferring the traditional method. There was also a disparity among other lecturers regarding their engagement with the tool. Furthermore, it took students a few weeks to become familiar with the embedded semi-flipped class approach which was much easier to implement by using Mentimeter. It was apparent that the embedded questions within the slides as well as the quiz competition have motivated students to make an extra effort into the unit and play an active role in the lectures. In addition, the interactive slides facilitated the inclusion of many formative assessments during the lecture timing which informed necessary ad-hoc adjustments to the lecture delivery by focusing on complex concepts that the students seemed to struggle with.

The interactive slides helped keep students involved, engaged, and entertained. The class environment became much more dynamic and interesting with many moments of fun and humour as a result of student contribution and interaction with the slides. Students appreciated the anonymity offered by the tool. The number of questions raised in lectures via the tool increased drastically as compared to the preceding term where students were reluctant to ask questions orally. However, a few students opted not to engage and used their mobile phones for non-related purposes. Sometimes, a few students needed to move around and recharge their mobile phones which was a bit distracting to the class. It was also observed that many anonymous questions raised in the lecture were not directly relating to the presented content but mainly seeking clarifications about forthcoming assessment tasks. 
Table 1. Interim survey results on a 5-point Likert scale

\begin{tabular}{|c|c|c|c|c|c|c|c|}
\hline Question & 1 & 2 & 3 & 4 & 5 & Mean & SD \\
\hline \multirow[t]{2}{*}{ Mentimeter improved my learning experience } & 4 & 2 & 16 & 57 & 76 & \multirow{2}{*}{4.28} & \multirow{2}{*}{0.84} \\
\hline & $3 \%$ & $1 \%$ & $10 \%$ & $37 \%$ & $49 \%$ & & \\
\hline \multirow[t]{2}{*}{ The unit design increased my motivation to learn } & 5 & 1 & 6 & 75 & 68 & \multirow{2}{*}{4.29} & \multirow{2}{*}{0.79} \\
\hline & $3 \%$ & $1 \%$ & $4 \%$ & $48 \%$ & $44 \%$ & & \\
\hline \multirow[t]{2}{*}{ My Lecturer in this unit helped me to learn } & 4 & 0 & 5 & 52 & 94 & \multirow{2}{*}{4.50} & \multirow{2}{*}{0.83} \\
\hline & $3 \%$ & $0 \%$ & $3 \%$ & $34 \%$ & $61 \%$ & & \\
\hline \multirow{2}{*}{$\begin{array}{l}\text { Adopting semi-flipped class model in lectures helped } \\
\text { me to learn }\end{array}$} & 4 & 2 & 17 & 84 & 48 & \multirow{2}{*}{4.10} & \multirow{2}{*}{0.89} \\
\hline & $3 \%$ & $1 \%$ & $11 \%$ & $54 \%$ & $31 \%$ & & \\
\hline \multirow[t]{2}{*}{ Overall, I am satisfied with the quality of this unit } & 4 & 0 & 8 & 87 & 56 & \multirow{2}{*}{4.23} & \multirow{2}{*}{0.77} \\
\hline & $3 \%$ & $0 \%$ & $5 \%$ & $56 \%$ & $36 \%$ & & \\
\hline
\end{tabular}

The tool seemed to have a positive impact on student academic achievements. The student success rate increased from 93 percent in the previous term to 98 percent in the term where the tool was used. Likewise, the overall average grades significantly increased from 56 percent to 70 percent. Furthermore, complete elimination of student vulnerability to academic misconduct was achieved in comparison to the preceding term where 30 suspicious cases were reported. In addition, the average attendance rate significantly increased to an average of 80 percent as compared to 25 percent in the previous term.

\section{The Interim Student Evaluation}

During the middle of the term, an anonymous interim online survey was disseminated to all students enroled in the unit to get feedback about their learning experience in the unit until then. The survey aimed to identify areas of improvement in the unit delivery that could be taken into consideration for the remainder of the term. The survey included a few five-point Likert scale questions to rate their level of agreement as follows: 1: strongly disagree, 2: disagree, 3: neither agree nor disagree, 4: agree and 5: strongly agree. In addition, the survey included a few open-ended questions aiming to collect richer data from students. 155 students attended this survey with a response rate of 64 percent. Table 1 demonstrates the results from that survey.

By analysing the numerical data, the mean of student responses was calculated against each question to measure the central tendency. The mean of each question was above 4 , which indicated that students were satisfied with the unit design, the quality of teaching, and the adoption of the semi-flipped class model. The standard deviation of each aspect shows that the individual responses, on average, were below 1 point away from the mean, which indicates that most surveyed respondents were satisfied with each aspect. The overall student satisfaction was calculated as 4.23 out of 5 which is higher than the university benchmark, currently set at 4 . Students were also asked to rate the extent of their agreement that Mentimeter improved their learning experience. 49 percent of the surveyed students strongly agreed and 37 percent agreed that Mentimeter has improved their learning experience with a calculated mean of 4.28. In addition, 95 percent of students were satisfied that the lecturer helped them to learn with a calculated mean of 4.5 out of 5 , being the most satisfactory aspect in the unit. 92 percent of students were satisfied that the unit design increased their motivation to learn.

Furthermore, students were also asked an open-ended question: "What are the best aspects of this unit?". A thematic analysis was conducted, and all students' comments were coded. In addition, a frequency analysis was conducted which indicated that Mentimeter was explicitly mentioned in 37 out of the 155 given comments amounting to 24 percent which validates the findings from the Likert Scale questions. Students valued the quality of teaching, regular feedback, support from teaching staff, and the engaging and motivating class environment, all of which are connected to the introduction of Mentimeter in the classroom. One student highly regarded the use of Mentimeter and associated quiz feature by saying: "Mentimeter is the main aspect of the unit. It really helps me to share my views and thoughts about the subject and the quizzes conducted in the lecture classes are also a great move to know each topic in the subject". Another student indicated that the tool addressed the social barrier problem by stating "Mentimeter is one of the best things I find really interesting in this unit. I can express my ideas, questions without any hesitation". A third 
Table 2. The themes and associated codes of the open-ended questions

\begin{tabular}{|c|c|}
\hline Themes and codes & Frequency \\
\hline The improved attainment of the unit learning outcomes & 17 \\
\hline Improved learning abilities & 4 \\
\hline Increased knowledge & 4 \\
\hline Dynamic learning environment & 4 \\
\hline Improved learning experience & 5 \\
\hline The enjoyable learning experience & 23 \\
\hline Enjoyable lecture classroom & 5 \\
\hline Interesting learning environment & 9 \\
\hline Innovative and engaging way of learning & 5 \\
\hline Integrative class environment & 4 \\
\hline The increased motivation for learning & 15 \\
\hline Improved engagement & 2 \\
\hline Encouraged participation in lecture & 9 \\
\hline Increased motivation & 4 \\
\hline The active learning facilitated by the quiz feature & 14 \\
\hline Spontaneous participation through quiz feature & 7 \\
\hline Learning through quiz & 2 \\
\hline Helpful quiz & 1 \\
\hline Encouraging quiz & 2 \\
\hline Recapping content through quiz & 1 \\
\hline Interesting quiz & 1 \\
\hline The facilitation of teacher-student two-way communication and instant feedback & 14 \\
\hline Instant feedback & 2 \\
\hline Two-way communication between students and lecturers & 3 \\
\hline Active discussion in class & 2 \\
\hline Improved learning through two-way communication & 2 \\
\hline Asking questions to lecturers without hesitation & 5 \\
\hline The discouragement of cheating & 4 \\
\hline Mentimeter discouraged cheating & 3 \\
\hline Increased motivation to improve integrity & 1 \\
\hline
\end{tabular}

student provided similar feedback by saying "The use of Mentimeter is encouraging every student to participate in the class lecture". Most interestingly, some students opined that Mentimeter was effective in maintaining their academic integrity. Specifically, those students commended the innovative way of teaching and the instant given feedback facilitated by the tool that deterred students from cheating in the unit. The themes and the associated codes are presented in Table 2.

In summary, Table $\mathbf{2}$ shows six distinct themes that emerged from the analysis representing the key practical implications of using the tool as listed below:

1. The improved attainment of the unit learning outcomes.

2. The enjoyable learning experience.

3. The increased motivation for learning.

4. The active learning facilitated by the quiz feature.

5. The facilitation of teacher-student two-way communication and instant feedback.

6. The discouragement of cheating.

Regarding student responses to the second open-ended question "What aspects of this unit are in most need of improvement?", the vast majority of students stated they are happy with the unit design and delivery approach and therefore no improvement is needed. One student, however, indicated that more student 


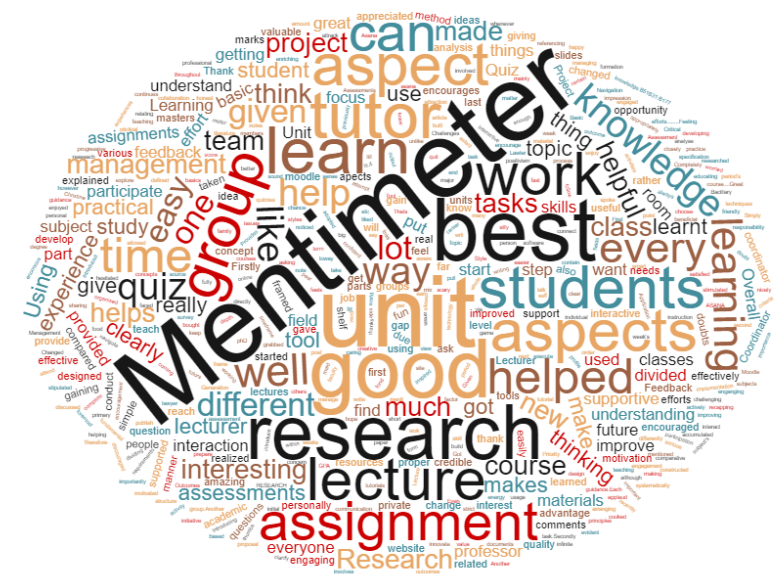

Figure 1. Word cloud of the best aspect of the unit as per the final evaluation

participation was needed in his class for Mentimeter to be used more effectively. Another student suggested the inclusion of all lecture slides in the interactive presentations.

\section{Final Student Evaluation}

Towards the end of the term, students were asked to participate in a standard anonymous final evaluation survey regarding the unit. 146 students attended the survey with a response rate of 61 percent. The results revealed that the overall student satisfaction increased to 4.6 out of 5 as compared to 4.23 out of 5 in the interim evaluation and 4.4 out of 5 in the final evaluation of the preceding term. Furthermore, students were asked an open-ended question "What are the best aspects of this unit?". The survey collected 95 responses to this question, 44 responses (amounting to 46 percent) of which mentioned Mentimeter as the best aspect of the unit as compared to 24 percent of responses in the interim evaluation. Student responses are illustrated in the Word Cloud of Figure 1. The results indicate that the students, at the beginning of the term, were not familiar with the tool and it took them a bit of time to get used to the technology and the unfamiliar delivery mode. One student commented, "Interactive lectures and tutorials with Mentimeter have been so enriching and major attraction. This unit has been the best so far in my whole course of Project Management". Many other students made similar comments and asserted the enjoyable learning environment achieved by the use of the tool. Furthermore, a template analysis of student responses was conducted using the six themes generated from the interim survey as an initial coding template. The template analysis validated all the identified themes in the interim survey and there was no need to refine the themes further. In addition, the analysis suggested that no new themes relating to Mentimeter could be identified.

Regarding student responses to the second open-ended question "What aspects of this unit are in most need of improvement?", the results were almost identical to the result obtained from the interim survey where most students confirmed that they were satisfied with the delivery of lectures. However, one student suggested using Mentimeter in all lectures which indicates that the respective lecturer preferred to use static slides. Another student requested more interaction in tutorial classes which is understood given the fact that Mentimeter was only used in the delivery of main lectures.

\section{DISCUSSION}

This study aims to examine the practical implications of using Mentimeter on the learning experience of international students. This section discusses the identified practical implications and the key areas of improvement.

\section{The Improved Attainment of the Unit Learning Outcomes}

This study indicates that the introduction of Mentimeter had a positive impact on the students' attainment of the unit learning outcomes. The tool substantially increased the student success rate in the unit as 
compared to the success rate in the previous term. The results also revealed that the tool helped the lecturers to be more effective in explaining complex concepts which was facilitated by students' willingness to learn and their active participation in the discussion. It was also beneficial in preparing students for assessments and conducting regular formative assessments to gauge the learning of students which is consistent with the findings of a previous study by Kuritza et al. (2020). In the final evaluation, one student commented "Mentimeter is the best software to learn and understand the unit aspects and requirements". Another student said, "Mentimeter is a good tool which is used to encourage students to focus on their study". This implication is of utmost importance to the international students who undergo several adjustments to cope with the unfamiliar education systems. The attainment of learning outcomes by the international students may be compromised because of their competing priorities such as external work commitments, settling in a new country, and study load (Brimble, 2016; Hosny \& Fatima, 2014). Their ability to cope up with such challenges determined their academic success (Introna et al., 2003). It was therefore evident that the introduction of the interactive tool has helped address their needs.

\section{The Enjoyable Learning Experience}

Teaching research subjects may be challenging and monotonous due to the dry nature of the content (Sillaots, 2014). However, it was evident that the employment of Mentimeter in this unit was perceived by students as a game-based tool that has brought significant excitement and joy to the class environment. In the final evaluation, one student said, "Mentimeter was a great idea and it helped a lot to make the lectures interesting and dynamic". Another student asserted that "The interactive lecture using Mentimeter was an interesting way to learn". This implication validates the findings of previous research that the tool was effective in making learning more enjoyable (Skoyles \& Bloxsidge, 2017). Moreover, the use of visual representation by word clouds as facilitated by the tool attracted a positive reaction from the students which provided another layer of excitement during the lectures. This finding is consistent with the findings of a previous study by Funnell (2017). As tertiary education systems in Australia are entirely different from that of most Asian countries (Wang et al., 2015; Wang \& Shan, 2007; Wong, 2004; Yu \& Wright, 2016), international students face 'academic shock' (Sovic, 2008). The academic transition creates anxiety in international students (Khawaja \& Stallman, 2011) which impedes their learning experiences. The findings of this study suggest that international students enjoy the learning experiences created by the interactive tool. The interactive tool made the class environment much more welcoming and enjoyable for the students. The evidence from this study implies that the interactive tool has the potential to ameliorate international students' learning experiences, thus enhancing learning abilities and knowledge.

\section{The Increased Motivation for Learning}

One of the most pressing reasons for deploying Mentimeter in higher education is to improve students' engagement and interaction in the classroom to stimulate the students' appetite to learn. The multiple positive comments from students inferred that Mentimeter promoted students' interaction, facilitated better engagement, enhanced class participation, reduced passive learning, and helped gauge their understanding of the content progressively. Students found the unit much more engaging and innovative as compared to all other units they have experienced as a result of introducing the interactive slides. One student responded to the final evaluation question about the best aspect of the unit by stating "First and foremost is Mentimeter which encouraged me to attend classes". Another student commented, "The use of Mentimeter is encouraging every student to participate in the class lecture". The latter comment was echoed multiple times by other students in the final evaluation. This implication resonates with a wide range of studies about the impact of Mentimeter on improving students' engagement (Gokbulut, 2020; Khalili \& Ostafichuk, 2018; Skoyles \& Bloxsidge, 2017; Van Daele et al., 2017; Wood, 2020). International students confront several challenges such as language barrier, different education systems, socio-cultural adaptation, various adjustments, transportation, finance, and many more (Gautam et al., 2016). These challenges are potentially significant in their ability to impact a student's confidence and concentration, thus causing them to become withdrawn or side-tracked from their studies (Cowley \& Hyams-Ssekasi, 2018). Given the fact that international students face many academic and non-academic challenges, it is highly likely that these students may feel disengaged and demotivated in their studies which may lead them to leave their 
universities at some point in time (Schulte \& Choudaha, 2014). This study indicates that the interactive tool clearly encouraged the international students to attend the classes and improved their motivation.

\section{The Active Learning Facilitated by the Quiz Feature}

The quiz functionality of Mentimeter enhanced students' learning and provided them with an interesting and engaging learning platform. Through some questions in the form of a quiz, educators can break up the monotonous environment of the class (Funnell, 2017). The quiz functionality of Mentimeter provided students with the opportunity for real-time feedback on their learning (Kuritza et al., 2020). The real-time quiz at the end of the lecture was valued by the students in this study as a means of recapping the learned content and reinforcing understating. One student commented in the final evaluation that "The online quizzes does [sic] not feel like a scary quiz but it feels more of a game that the student would want to participate on. I personally find it useful and very engaging way to learn". Another student said, "Mentimeter interaction with real-time quiz was one of the interesting factors". The use of the quiz feature in each lecture facilitated students' learning and active participation in the class activities. In most of the recent studies, the quiz feature of Mentimeter was emphasised as an added advantage (Funnell, 2017). One of the prevalent challenges international students face in a foreign education system is the language barrier. The international students' passive class participation can be attributed to the language barrier (Briguglio \& Smith, 2012). They feel uncomfortable in participating in the class discussion because of their language barrier (Hellsten \& Prescott, 2004; Robertson et al., 2000) which obstructs their active participation in the class discussion. This challenge seems to be diminished with the use of the 'quiz' functionality of Mentimeter. Not only did the quizzes help the international students recap their learned content, but they also substantially increased their class participation as evidenced by the students' comments. Therefore, the findings indicate that the quiz feature of the tool promoted their active learning and enhanced their enthusiasm to engage in-class activities.

\section{The Facilitation of Teacher-Student Two-Way Communication and Instant Feedback}

Anonymity is one of the popular features of the Mentimeter tool. Students highly regarded this feature as their identities during class participation are not disclosed to their peers and lecturers. Mentimeter creates a user-friendly platform for students to ask anonymous questions directly to the lecturers (Van Daele et al., 2017). In this regard, a student left the following comment in the final evaluation "we were not hesitated to ask questions". In the same evaluation, another student stated "It allowed me to post some basic silly doubts". Many previous studies echoed the benefits of the anonymity feature (Funnell, 2017; Gokbulut, 2020; Khalili \& Ostafichuk, 2018; Skoyles \& Bloxsidge, 2017). With this feature, shy and anxious students in the classroom feel more comfortable and their participation in the class increases (Funnell, 2017; Skoyles \& Bloxsidge, 2017; Wood, 2020) as students sometimes feel they are under pressure to ask or answer questions in the classroom which is an issue for certain cultures (Huang et al., 2008). Students can see other anonymous students' responses which create a more collaborative learning environment (Khalili \& Ostafichuk, 2018). Furthermore, students highly regarded the instant feedback provided by their lecturers on their questions and answers to the posed questions as facilitated by the tool which is consistent with the findings of previous studies (Kuritza et al., 2020; Wood, 2020). A student commented in the final evaluation that "I think Mentimeter introduced by the unit coordinator is very good for two-way communication and really helpful for learning in creative manner". As previously discussed, the tertiary education systems in Asian countries are different from those of Australia. Asian countries' education systems are mostly teacher-centred while teachers in Australian universities follow a student-centred learning approach (Wong, 2004). The difference in teaching and learning style poses a significant challenge to international students (Wang et al., 2015). The language barrier further exacerbates the situation. Because of their language barrier, the international students are hesitant to speak in the class and as a result, they hardly communicate with teachers (Sawir, 2005) which may deter students from asking questions to their teachers. The implementation of the interactive tool demonstrates that students were comfortable asking questions to their teachers. The anonymity feature helped them ask questions without being exposed which seemed to be a sense of relief to the international students. The results suggest that the interactive tool helped make a connection between the teachers and the students which improved the communication between them. The students' comments 
indicate that Mentimeter facilitated two-way communication and the students felt more inclusive in the class.

\section{The Discouragement of Cheating}

One of the interesting findings of the study is that Mentimeter deterred students from cheating. A student commented in the interim evaluation "Mentimeter and interactive class sessions encouraged me to keep my work original". Arguably, this is a significant implication since a recent study found that international students are more vulnerable to contract cheating (Bretag et al., 2014). Indeed, after the use of the tool for the first time, not a single suspicious case of contract cheating was reported as compared to 30 reported cases in the previous term. It could be argued that that the reduced number of academic misconduct cases can partially be attributed to the deployment of Mentimeter. By engaging in-class formative assessments using the tool, students developed a better understanding of the content and became more confident of their abilities to undertake the assessment tasks on their own. There is, however, a dearth of literature that examines the correlation between the implementation of student response systems in higher education and academic integrity, and this study can be a starting point to initiate further research.

\section{Areas for Improvement}

Although the introduction of interactive technology provided students with numerous benefits as compared to the previous terms, there are some areas identified in this case study that require attention. Both students and the teaching team needed to have adequate induction and training regarding the use of technology to use it effectively as intended. This finding is in line with the recommendation of a recent study by Hof (2020) who suggested providing teaching staff with proper digital support to use Mentimeter efficiently in the classroom. The use of the tool should be integrated with other measures to counter the observed limitations including, but not limited to, the introduction of the semi-flipped class model and linking assessment tasks with the lecture content. In this study, despite its obvious benefits, Mentimeter was inefficient to attract a few students to engage in the class. Rather, those students availed themselves of the opportunity for using their mobile phones in class for non-academic activities. It was also impossible to identify disengaged students or free riders because of the anonymity feature in the tool. This may, however, be mitigated by asking all students to provide their real names instead of nicknames when participating in the quiz competitions. Another potential problem of using interactive technology is that it may limit students' opportunity to share their thoughts verbally and improve their oral communication skills. This limitation, however, can be addressed by allowing students to discuss the learned content in small groups and embed oral presentations within the assessment tasks.

\section{CONCLUSION}

This case study demonstrated how interactive technology was introduced in teaching a research method unit to international postgraduate students and examined its practical implications and limitations on the learning of international students. The study advocated for the need of embedding interactive technology in contemporary education to stimulate students and improve their learning experience and attainment of learning outcomes. The study reveals that the introduction of interactive technology had a significant positive impact on student perceptions of their learning experience. The technology was very helpful in encouraging students to attend classes and stimulate them to actively participate in class discussions. The study suggests that the technology facilitates a swift pedagogical transition from a teacher-centred learning to a more student-centred environment. The international students perceived interactive technology as an innovative way of teaching and overcoming cultural and communication barriers. It encouraged them to attend classes and be active participants. It helped them feel included and understand complex topics in a joyful setting. The technology has shown excellent potential in stimulating students to genuinely engage in their studies and uplift their academic integrity. However, some students still opted to use their devices for non-academic activities which suggests that the tool on its own cannot stimulate all students to engage. 


\section{LIMITATIONS AND FUTURE RESEARCH}

The findings of this study have limitations considering that it was based on a single case study. The case study only examined one of the available tools and the scope of the research did not allow any comparison with other tools to evaluate their different features. However, this research can be considered as a reference point for future studies. Specifically, further research is encouraged to examine and contrast the impact and challenges of using various interactive technological tools in different settings including undergraduate vs postgraduate, small vs. large classes, on-campus vs online classes, and international vs. domestic students.

Author contributions: All authors were involved in concept, design, collection of data, interpretation, writing, and critically revising the article. All authors approve final version of the article.

Funding: The authors received no financial support for the research and/or authorship of this article.

Declaration of interest: Authors declare no competing interest.

Data availability: Data generated or analysed during this study are available from the authors on request.

\section{REFERENCES}

Abrahamson, A. L. (2006). A brief history of networked classrooms: Effects, cases, pedagogy and implications. In D. A. Banks (Ed.), Audience response systems in higher education: Applications and cases (pp. 1-25). Information Science. https://doi.org/10.4018/978-1-59140-947-2.ch001

Andrade, M. (2006). International students in English-speaking universities: Adjustment factors. Journal of Research in International Education, 5(2), 131-154. https://doi.org/10.1177/1475240906065589

Baxter, P., \& Jack, S. (2008). Qualitative case study methodology: Study design and implementation for novice researchers. The Qualitative Report, 13(4), 544-559. https://doi.org/10.46743/2160-3715/2008.1573

Blasco-Arcas, L., Buil, I., Hernández-Ortega, B., \& Sese, F. J. (2013). Using clickers in class. The role of interactivity, active collaborative learning and engagement in learning performance. Computers \& Education, 62, 102-110. https://doi.org/10.1016/j.compedu.2012.10.019

Brady, M., Seli, H., \& Rosenthal, J. (2013). "Clickers" and metacognition: A quasi-experimental comparative study about metacognitive self-regulation and use of electronic feedback devices. Computers \& Education, 65, 56-63. https://doi.org/10.1016/j.compedu.2013.02.001

Bretag, T., Mahmud, S., Wallace, M., Walker, R., McGowan, U., East, J., Green, M., Partridge, L., \& James, C. (2014). 'Teach us how to do it properly!' An Australian academic integrity student survey. Studies in Higher Education, 39(7), 1150-1169. https://doi.org/10.1080/03075079.2013.777406

Briguglio, C., \& Smith, R. (2012). Perceptions of Chinese students in an Australian university: Are we meeting their needs?. Asia Pacific Journal of Education, 32(1), 17-33. https://doi.org/10.1080/02188791.2012.655237

Brimble, M. (2016). Why students cheat. An exploration of the motivators of student academic dishonesty in higher education. In: Bretag T. (Ed.), Handbook of Academic Integrity (pp. 1-14). Springer. https://doi.org/10.1007/978-981-287-079-7_58-1

Cain, J., Black, E. P., \& Rohr, J. (2009). An audience response system strategy to improve student motivation, attention, and feedback. American Journal of Pharmaceutical Education, 73(2), 21. https://doi.org/10.5688/aj730221

Cowley, P., \& Hyams-Ssekasi, D. (2018). Motivation, induction, and challenge: Examining the initial phase of international students' educational sojourn. Journal of International Students, 8(1), 109-130. https://doi.org/10.32674/jis.v8i1.154

Creswell, J. W. (2009). Research design: Qualitative, quantitative, and mixed methods approaches (3rd ed.). SAGE. 
DeBourgh, G. A. (2008). Use of classroom "clickers" to promote acquisition of advanced reasoning skills. Nurse Education in Practice, 8(2), 76-87. https://doi.org/10.1016/j.nepr.2007.02.002

Duggan, P. M., Palmer, E., \& Devitt, P. (2007). Electronic voting to encourage interactive lectures: A randomised trial. BMC Medical Education, 7(1), 1-9. https://doi.org/10.1186/1472-6920-7-25

Fies, C., \& Marshall, J. (2006). Classroom response systems: A review of the literature. Journal of Science Education and Technology, 15(1), 101-109. https://doi.org/10.1007/s10956-006-0360-1

Funnell, P. (2017). Using audience response systems to enhance student engagement and learning in information literacy teaching. Journal of Information Literacy, 11(2), 28-50. https://doi.org/10.11645/11.2.2238

Gautam, C., Lowery, C. L., Mays, C., \& Durant, D. (2016). Challenges for global learners: A qualitative study of the concerns and difficulties of international students. Journal of International Students, 6(2), 501-526. https://doi.org/10.32674/jis.v6i2.368

Gokbulut, B. (2020). The effect of Mentimeter and Kahoot applications on university students' e-learning. World Journal on Educational Technology: Current Issues, 12(2), 107-116. https://doi.org/10.18844/wjet.v12i2.4814

Gomes, C., Berry, M., Alzougool, B., \& Chang, S. (2014). Home away from home: International students and their identity-based social networks in Australia. Journal of International Students, 4(1), 2-15. https://doi.org/10.32674/jis.v4i1.493

Heaslip, G., Donovan, P., \& Cullen, J. G. (2014). Student response systems and learner engagement in large classes. Active Learning in Higher Education, 15(1), 11-24. https://doi.org/10.1177/1469787413514648

Hellsten, M., \& Prescott, A. (2004). Learning at university: The international student experience. International Education Journal, 5(3), 344-351.

Heng, T. T. (2018). Different is not deficient: Contradicting stereotypes of Chinese international students in US higher education. Studies in Higher Education, 43(1), 22-36. https://doi.org/10.1080/03075079.2016.1152466

Hof, Y. T. (2020). Managing a teaching technologies assimilation program at nursing school in Israel. Journal of US-China Public Administration, 17(2), 63-70. https://doi.org/10.17265/1548-6591/2020.02.003

Hosny, M., \& Fatima, S. (2014). Attitude of students towards cheating and plagiarism: University case study. Journal of Applied Sciences, 14(8), 748-757. https://doi.org/10.3923/jas.2014.748.757

Huang, Q., Davison, R. M., \& Gu, J. (2008). Impact of personal and cultural factors on knowledge sharing in China. Asia Pacific Journal of Management, 25(3), 451-471. https://doi.org/10.1007/s10490-008-90952

Hunsu, N. J., Adesope, O., \& Bayly, D. J. (2016). A meta-analysis of the effects of audience response systems (clicker-based technologies) on cognition and affect. Computers \& Education, 94, 102-119. https://doi.org/10.1016/j.compedu.2015.11.013

Introna, L., Hayes, N., Blair, L., \& Wood, E. (2003). Cultural attitudes towards plagiarism: Developing a better understanding of the needs of students from diverse cultural backgrounds relating to issues of plagiarism. Lancaster University.

Kambouropoulos, A. (2014). An examination of the adjustment journey of international students studying in Australia. The Australian Educational Researcher, 41(3), 349-363. https://doi.org/10.1007/s13384013-0130-z 
Khalili, M., \& Ostafichuk, P. M. (2018). Improving class participation by using an online interactive platform. Proceedings of the Canadian Engineering Education Association (CEEA), Vancouver, 1-5. https://doi.org/10.24908/pceea.v0i0.13095

Khawaja, N. G., \& Stallman, H. M. (2011). Understanding the coping strategies of international students: A qualitative approach. Journal of Psychologists and Counsellors in Schools, 21(2), 203-224. https://doi.org/10.1375/ajgc.21.2.203

Kulatunga, U., \& Rameezdeen, R. (2014). Use of clickers to improve student engagement in learning: Observations from the built environment discipline. International Journal of Construction Education and Research, 10(1), 3-18. https://doi.org/10.1080/15578771.2013.826754

Kuritza, V. C., Cibich, D. P., \& Ahmad, K. A. (2020). Interactive presentation digital tool Mentimeter perceived as accessible and beneficial for exam preparation by medical students. Advances in Educational Research and Evaluation, 1(2), 63-67. https://doi.org/10.25082/AERE.2020.02.002

Lin, X., \& Lin, C. (2020). Communication theories applied in Mentimeter to improve educational communication and teaching effectiveness. Proceedings of the 4th International Conference on Culture, Education and Economic Development of Modern Society. Russia, 416. https://doi.org/10.2991/assehr.k.200316.191

Lincoln, Y., \& Guba, E. G. (1985). Naturalistic inquiry. SAGE. https://doi.org/10.1016/0147-1767(85)90062-8

Little, C. (2016). Mentimeter smartphone student response system: A class above clickers. Compass: Journal of Learning and Teaching, 9(13), 1-3. https://doi.org/10.21100/compass.v9i13.328

Mayer, R. E., Stull, A., DeLeeuw, K., Almeroth, K., Bimber, B., Chun, D., \& Zhang, H. (2009). Clickers in college classrooms: Fostering learning with questioning methods in large lecture classes. Contemporary Educational Psychology, 34(1), 51-57. https://doi.org/10.1016/j.cedpsych.2008.04.002

Mayhew, E. (2019). No longer a silent partner: How Mentimeter can enhance teaching and learning within political science, Journal of Political Science, 15(4), 546-551. https://doi.org/10.1080/15512169.2018.1538882

McGarr, O. (2009). A review of podcasting in higher education: Its influence on the traditional lecture. Australasian Journal of Educational Technology, 25(3), 309-321. https://doi.org/10.14742/ajet.1136

Novera, I. A. (2004). Indonesian postgraduate students studying in Australia: An examination of their academic, social and cultural experiences. International Education Journal, 5(4), 475-487.

Nowell, L. S., Norris, J. M., White, D. E., \& Moules, N. J. (2017). Thematic analysis: Striving to meet the trustworthiness criteria. International Journal of Qualitative Methods, 16(1), 1-13. https://doi.org/10.1177/1609406917733847

ONF, (2014). The use of triangulation in qualitative research. Oncology Nursing Forum, 41(5), 545-547. https://doi.org/10.1188/14.ONF.545-547

Paschal, C. B. (2002). Formative assessment in physiology teaching using a wireless classroom communication system. Advances in Physiology Education, 26(4), 299-308. https://doi.org/10.1152/advan.00030.2002

Petersohn, B. (2008). Classroom performance systems, library instruction, and instructional design: A pilot study. Portal: Libraries and the Academy, 8(3), 313-324. https://doi.org/10.1353/pla.0.0007

Phakiti, A., \& Li, L. (2011). General academic difficulties and reading and writing difficulties among Asian ESL postgraduate students in TESOL at an Australian university. RELC Journal, 42(3), 227-264. https://doi.org/10.1177/0033688211421417

Poyrazli, S., \& Grahame, K. M. (2007). Barriers to adjustment: Needs of international students within a semiurban campus community. Journal of Instructional Psychology, 34(1), 28. 
Rashid, T., \& Asghar, H. M. (2016). Technology use, self-directed learning, student engagement and academic performance: Examining the interrelations. Computers in Human Behavior, 63, 604-612. https://doi.org/10.1016/j.chb.2016.05.084

Reay, N. W., Bao, L., Li, P., Warnakulasooriya, R., \& Baugh, G. (2005). Toward the effective use of voting machines in physics lectures. American Journal of Physics, 73(6), 554-558. https://doi.org/10.1119/1.1862638

Regmi, K. (2014). Triangulation in healthcare research: What does it achieve? SAGE. https://doi.org/10.4135/978144627305014534931

Robertson, M., Line, M., Jones, S., \& Thomas, S. (2000). International students, learning environments and perceptions: A case study using the Delphi technique. Higher Education Research and Development, 19(1), 89-102. https://doi.org/10.1080/07294360050020499

Rudolph, J. (2018). A brief review of Mentimeter-A student response system. Journal of Applied Learning \& Teaching, 1(1), 35-37. https://doi.org/10.37074/jalt.2018.1.1.5

Sanner, S., \& Wilson, A. (2008). The experiences of students with English as a second language in a baccalaureate nursing program. Nurse Education Today, 28(7), 807-813. https://doi.org/10.1016/j.nedt.2008.03.004

Sawir, E. (2005). Language difficulties of international students in Australia: The effects of prior learning experience. International Education Journal, 6(5), 567-580.

Sawir, E., Marginson, S., Forbes-Mewett, H., Nyland, C., \& Ramia, G. (2012). International student security and English language proficiency. Journal of Studies in International Education, 16(5), 434-454. https://doi.org/10.1177/1028315311435418

Schulte, S., \& Choudaha, R., 2014. Improving the experiences of international students. Change: The Magazine of Higher Learning, 46(6), 52-58. https://doi.org/10.1080/00091383.2014.969184

Sillaots, M. (2014). Achieving flow through gamification: A study on re-designing research methods courses. European Conference on Games Based Learning, 2, 538-545. https://search.proquest.com/docview/1674245409?pqorigsite=gscholar\&fromopenview=true

Skoyles, A., \& Bloxsidge, E. (2017). Have you voted? Teaching OSCOLA with Mentimeter. Legal Information Management, 17(4), 232-238. https://doi.org/10.1017/S1472669617000457

Sovic, S. (2008). Coping with stress: The perspective of international students. Art, Design \& Communication in Higher Education, 6(3), 145-158. https://doi.org/10.1386/adch.6.3.145/1

Van Daele, T., Frijns, C., \& Lievens, J. (2017). How do students and lecturers experience the interactive use of handheld technology in large enrolment courses? British Journal of Educational Technology, 48(6), 1318-1329. https://doi.org/10.1111/bjet.12500

Wang, C. C., Andre, K., \& Greenwood, K. M. (2015). Chinese students studying at Australian universities with specific reference to nursing students: A narrative literature review. Nurse Education Today, 35(4), 609-619. https://doi.org/10.1016/j.nedt.2014.12.005

Wang, T., \& Shan, X. (2007). Exploring Chinese postgraduate students' academic adjustment experiences in Australia. In The Higher Education Research and Development Society of Australasia Inc, 2007 International Conference (pp. 624-633).

Winn, S. (1995). Learning by doing: Teaching research methods through student participation in a commissioned research project. Studies in Higher Education, 20(2), 203-214. https://doi.org/10.1080/03075079512331381703 
Wong, J. K. K. (2004). Are the learning styles of Asian international students culturally or contextually based?. International Education Journal, 4(4), 154-166.

Wood, A. (2020). Utilizing technology-enhanced learning in geography: Testing student response systems in large lectures. Journal of Geography in Higher Education, 44(1), 160-170. https://doi.org/10.1080/03098265.2019.1697653

Yanagi, M., \& Baker, A. A. (2016). Challenges experienced by Japanese students with oral communication skills in Australian universities. TESOL Journal, 7(3), 621-644. https://doi.org/10.1002/tesj.229

Yazan, B. (2015). Three approaches to case study methods in education: Yin, Merriam, and Stake. The Qualitative Report, 20(2), 134-152. https://doi.org/10.46743/2160-3715/2015.2102

Yin. R. K. (2014). Case study research: Design and methods (5th ed.). SAGE.

Yourstone, S. A., Kraye, H. S., \& Albaum, G. (2008). Classroom questioning with immediate electronic response: Do clickers improve learning?. Decision Sciences Journal of Innovative Education, 6(1), 7588. https://doi.org/10.1111/j.1540-4609.2007.00166.x

Yu, B., \& Wright, E. (2016). Socio-cultural adaptation, academic adaptation and satisfaction of international higher degree research students in Australia. Tertiary Education and Management, 22(1), 49-64. https://doi.org/10.1080/13583883.2015.1127405

Yue, Y., \& Fan, S. (2010). Learning experiences of Chinese background international students in an Australian tertiary context. AARE2010, 1-16.

Zhang, Y., \& Mi, Y. (2010). Another look at the language difficulties of international students. Journal of Studies in International Education, 14(4), 371-388. https://doi.org/10.1177/1028315309336031

Zhou, Y., Jindal-Snape, D., Topping, K., \& Todman, J. (2008). Theoretical models of culture shock and adaptation in international students in higher education. Studies in Higher Education, 33(1), 63-75. https://doi.org/10.1080/03075070701794833

Correspondence: Samer Skaik, School of Engineering and Technology, Central Queensland University, Melbourne, Victoria 3000, Australia. E-mail: s.skaik@cqu.edu.au 